\title{
Is Khat chewing habit a risk factor for occlusal caries progression?
}

\author{
Khaled Rashad Al-Alimi ${ }^{1}$, Abdul Aziz Abdul Razak ${ }^{1}$, Roslan Saub ${ }^{2}$
}

1. Department of Restorative Dentistry, Faculty of Dentistry, University of Malaya, Kuala Lumpur, Malaysia.

2. Department of Community Oral Health \& Clinical Prevention, Faculty of Dentistry, University of Malaya, Kuala Lumpur, Malaysia.

\begin{abstract}
Backgrounds: People in Yemen and in East African countries chew khat more than five hours daily.

Objectives: The aim of this study was to assess the relationship between khat and occlusal caries progression.

Methods: A cohort study was carried out among 98 Yemeni khat chewers and 101 non-chewers aged 18-35 years old with early occlusal caries lesions. All participants answered questions on socio-demographic, khat, oral hygiene, sugar intake, and oral health knowledge at baseline. All posterior teeth with an early enamel lesion on occlusal surfaces detected by visual inspection at baseline were also subjected to DIAGNOdent assessment to confirm early lesion (DIAGNOdent reading 13-24). Participants were re-examined after 12 weeks. Caries progression was considered to occur when the DIAGNOdent reading was $>25$. Data were analyzed using Relative risk, Mann-Whitney U test, a Wilcoxon Signed-Rank test and logistic regression analysis.

Results: Occlusal caries progression incidence between khat chewers and non-chewers, with the relative risk was 1.68. There was no significant difference in occlusal caries progression on chewing side and non-chewing side among khat chewers. Khat chewing was a statistical predictor for those with low income.

Conclusion: Khat is a risk factor for occlusion caries progression among low income group.

Keywords: Khat, caries progression, DIAGNOdent pen.

DOI: https://dx.doi.org/10.4314/ahs.v18i4.25

Cite as: Al-Alimi KR, Razak. AAA, Saub R. Is Khat chewing habit a risk factor for occlusal caries progression? Afri Health Sci. 2018;18(4): 1036-1045. https://dx.doi.org/10.4314/abs.v18i4.25
\end{abstract}

\section{Introduction}

Khat chewing has become a habit to millions of people especially in Yemen and East African countries. With the development of tourism and globalization, this habit has spread across the world and now it can be found in country such as the UK and the Netherlands where the communities have descended from settlers of African and Yemeni origins. ${ }^{1-3}$

\section{Corresponding author: \\ Khaled Rashad Al-Alimi \\ Department of Restorative Dentistry, \\ Faculty of Dentistry, University of Malaya, \\ 50603 - Kuala Lumpur, Malaysia \\ Telephone: +201016868972 \\ Fax Number: +603-79674532 \\ E-Mail: alalimi_khaled2005@yahoo.com}

Khat (Catha edulis) is an ever-green shrub that belongs to family Celastraceae. It grows in Yemen and Southern Arabia as well as in certain East African countries, such as Ethiopia, Somalia, Djibouti, and Kenya. Khat grows especially well in moist conditions and is generally cultivated along the mountain slopes at altitudes of $3500 \mathrm{ft}$ to $7000 \mathrm{ft}$ and varies in height from $3 \mathrm{ft}$ to $15 \mathrm{ft}$.

Khat leaves are habitually chewed by inhabitants in these regions because of their psycho-stimulant effect, similar to that produced by amphetamine-like substances. It is always chewed in one preferred side of the mouth. The left side of the mouth is the most frequently used side and only few people use the right side of their mouths for chewing. Young fresh leaves are chewed, formed to a bolus, and held in the lower buccal pouch unilaterally for three hours or longer.

Due to rampant practice of khat chewing especially in Yemen, it is thus essential to explore the effect of khat on oral health. Although there is extensive literature about

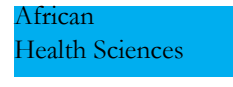

(C) 2018 Al-Alimi et al. Licensee African Health Sciences. This is an Open Access article distributed under the terms of the Creative commons Attribution License (https://creativecommons.org/licenses/BY/4.0), which permits unrestricted use, distribution, and reproduction in any medium, provided the original work is properly cited. 
khat, studies on its effect on oral health are still scarce. In vitro study done by Al-Alimi ${ }^{4}$ indicated that Khat chewing habit is associated with enamel demineralization at the tooth composite restoration interface. In addition, several cross-sectional studies have reported the association between khat chewing and dental caries. Such studies provide low evidence of the association. In addition, its role as a caries risk factor contributing to dental caries lesion progression has not been studied and documented yet. Hence, the aim of this study was to assess the relationship between khat and occlusal caries progression

\section{Materials and methods}

The study was approved by the research ethics committee of the University of Malaya (DFRD 1001/0009 (P).

A cohort study was conducted on Yemeni khat chewers (expose) and non-chewers (non- expose), aged between 18-35 years, with early occlusal caries. The participants of this study were recruited from dental private center and public hospital in Sana'a. All patients aged between 18-35, who have no systemic diseases and agreed to participate in the study, were screened for their chewing habits and white spots or early enamel lesions of the posterior tooth. Those participants who chewed khat with crystallized sugar, chewed it less often than twice a week, chewed khat on the right side or used both sides were excluded since the most common preferred side for chewers is on the left side.
The selection of teeth for both groups was done according to following inclusion and exclusion criteria. Any of the posterior teeth both in upper and lower jaws except third molars, with white spot or early enamel lesion were selected. Teeth with cavities, sealants, occlusal or buccal restorations, hypo-plastic surfaces, pathological abrasions or other structural defects, such as flourosis, were excluded.

The participants were clinically examined by one trained examiner, who was calibrated using 10 participant's khat chewers and 10 non-chewers that had no visible cavitation. The Examiner visually assessed each tooth selected and agreed on the criteria to be used. One week later the examiner reexamined the participants. Two sets of measurements for 10 participants were taken for teeth measured by DIAGNOdent Pen on two different occasions with one-week interval. The consistency of measurements was then estimated using the intra-class correlation coefficient. Excellent intra-class correlation coefficient was 0.90 .

The visual inspection method was used to screen and select the suitable posterior teeth with early enamel lesion for participation in this study. The teeth were lightly blowdried using a 3-in-1 syringe before the examination. The texture of the occlusal surfaces was felt tactilely without pressure using a probe according to the criteria proposed by Ekstrand et al. ${ }^{5}$ as shown in Table 1.

\section{Table 1 Visual inspection criteria (Ekstrand et al.)}

\begin{tabular}{ll}
\hline $\begin{array}{l}\text { Visual } \\
\text { Category }\end{array}$ & Visual Category Criteria \\
\hline 0 & $\begin{array}{l}\text { Translucency after prolonged drying with air (5s). No change or } \\
\text { slight change in enamel. }\end{array}$ \\
& $\begin{array}{l}\text { Discoloration or opacity is scarcely distinguishable if the surface } \\
\text { is wet, but after air drying it gets clearly visible }\end{array}$ \\
2 & $\begin{array}{l}\text { Discoloration or opacity is visible even if air drying is not used. } \\
3\end{array}$ \\
& $\begin{array}{l}\text { Grayish discoloration from the dentine below. Localized } \\
\text { breakdown of the enamel in discolored or opaque enamel. } \\
\text { Cavitation in the discolored or opaque enamel. The dentine is } \\
\text { exposed. }\end{array}$ \\
\hline
\end{tabular}


Tooth indicated as code 1, 2 in the visual inspection was subjected to DIAGNOdent ${ }^{\circledR}$, (KaVo, Biberach, Germany) assessment. DIAGNOdent pen was used to record the early enamel lesion and monitoring dental caries progression. DIAGNOdent readings between 0 and 12 indicated as sound tooth, 13-24 readings as initial demineralization and reading above 25 indicated as strong demineralization. Tooth was selected when the DIAGNOdent reading was between 13-24 at baseline. Caries progression was defined in this study was when the diagnodent reading at follow up was above 25 .

Before the DIAGNOdent reading was taken, the selected tooth was cleaned professionally using a rotating hand piece, a rubber cup, polishing paste (Cleanic ${ }^{\circledR}$, Hawe Neos Dental Bioggio, Switzerland), and plain water spray to remove plaque and stain. Then, the tooth was rinsed with copious water spray and blow-dried lightly. The interdental spaces were also dried following the manufacturer's instructions. The tip of the DIAGNOdent was placed perpendicular to the examination site and turned around in order to pick up the area where the caries lesion was the most advanced so that the highest DIAGNOdent reading could be recorded. The examined sites were identified and drawn in an examination sheet as a guide for the follow up reading. Three consecutive readings were taken for each examination site and the mean was calculated for each examination site.

Prior to taking the reading for occlusal caries among all participants, calibration of the device was done in-between all the participants according to the instructions given by the manufacturer. Accurate measurements within a long period of time can be ensured with calibrating the device against the ceramic standard prior the measurement session. Units of the display were compared to a ceramic calibration standard.

All participants completed a set of questionnaire to gathered information on socio-demographics factors (age, gender, education and income), chewing khat habit, diet habits, oral hygiene practice, and oral health knowledge at baseline. All participants of both groups were re-ex- amined after 12 weeks to monitor the occlusal caries progression. All teeth were re-examined using DIAGNOdent Pen only. Caries progression were then determined. If readings at this follow up was between 13-24 indicated no caries progression and if the reading was above 25 , it indicated caries progression.

Two parameters were calculated for the caries progression: 1) occlusal caries progression incidence - at least one tooth showed progression and occlusal caries progression rate - the percentage of teeth that progressed. The relative risk was used to measure the magnitude of the association between Khat chewing habit and incidence rate of caries progression. Mann-Whitney $U$ test was used to compare occlusal caries progression rate between Yemeni khat chewers and non-chewers. Wilcoxon Signed-Rank test was run to determine if there were differences in occlusal caries progression rate at chewing side and non-chewing side among khat chewers group. Confounding effects of socio-demographic variables was analyzed using bivariate analysis. Logistic regression analysis was used to assess the predictors related to caries progression. Confounder variables of oral hygiene practice, sugar intake and oral health knowledge were transformed to summated scales using Rasch Model. Rasch analysis model showed that the items were contributing meaningfully and working in the same direction to measure the intended construct for oral hygiene practice, sugar intake and oral health knowledge $e^{6,7}$ The significant level was set at $\mathrm{p}<0.05$

\section{Results}

The total number of participants in this study was 199, where 98 were chewers and 101 were in the non-chewer group. Table 2 shows the distribution of the sample characteristics of khat chewers and non-chewers. The distributions of the gender and education level were significantly different between the two groups. The percentage of female participants was higher in the non-chewers group $(71.3 \%)$. High percentage of chewers was university graduates, whereas, high percentage of non- chewers had a college degree. 
Table 2 Sample characteristics of khat chewers and non-chewers

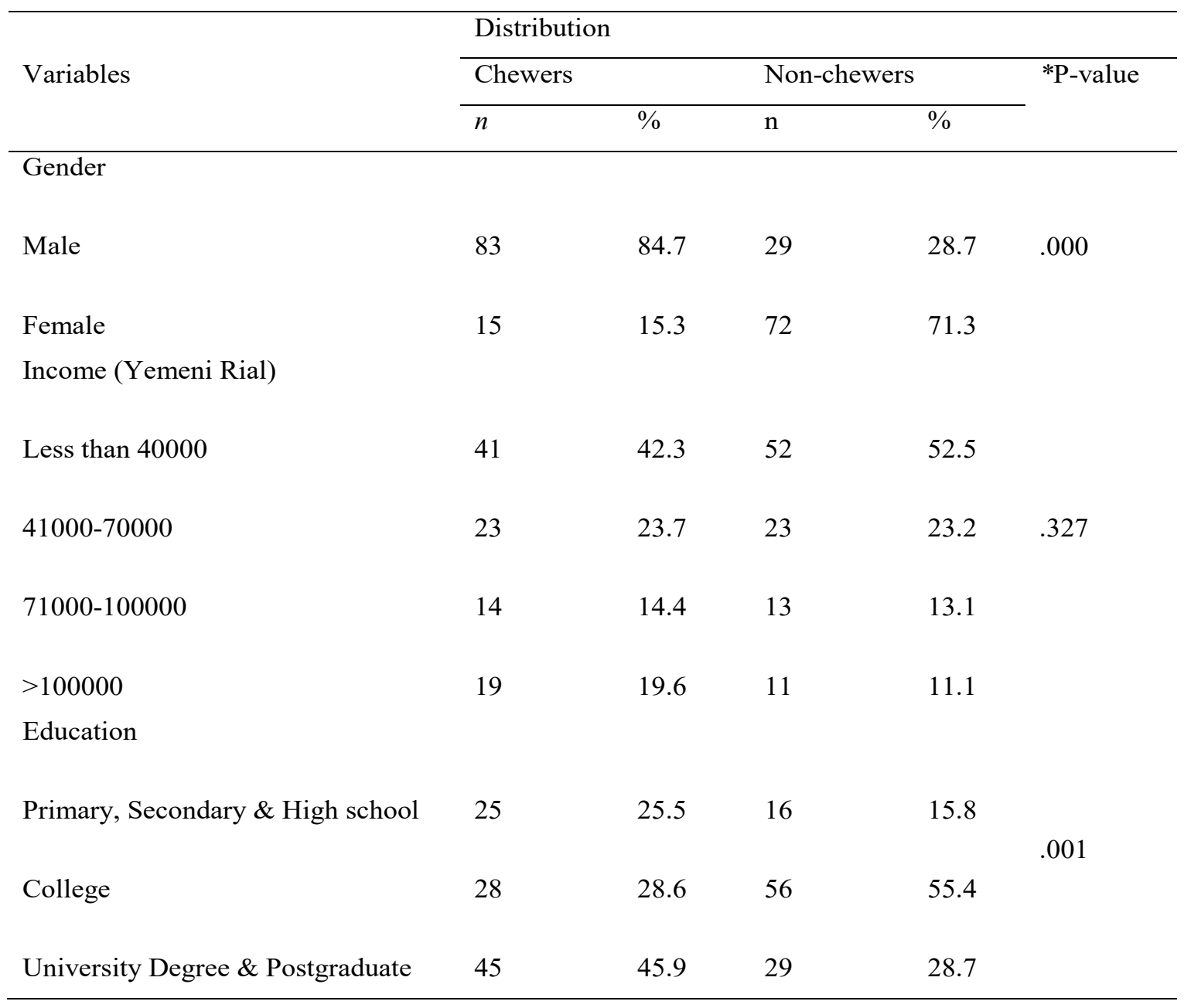

*Chi-square test

The occlusal caries progression incidence between khat chewers and non-chewers were $44.9 \%$ and $26.7 \%$ respectively, with the relative risk of the occlusal caries progression incidence at 1.68, indicating that khat chewers have
1.68 times increased risk for occlusal caries progression incidence (Table 3). The occlusal caries progression rate was significantly higher among khat chewers compared to non-chewers as shown in Fig. 1.

Table 3 Relative risk of occlusal caries progression

\begin{tabular}{|c|c|c|c|c|c|c|c|}
\hline \multirow[t]{3}{*}{ Group } & \multicolumn{4}{|c|}{ Caries Progression } & \multirow[t]{3}{*}{ Total } & \multirow[t]{3}{*}{ RR } & \multirow[t]{3}{*}{ *P-value } \\
\hline & \multicolumn{2}{|c|}{ Progress } & \multicolumn{2}{|c|}{ No progress } & & & \\
\hline & $\mathrm{n}$ & $(\%)$ & $\mathrm{n}$ & $(\%)$ & & & \\
\hline Chewer & 44 & (44.9) & 54 & $(55.1)$ & 98 & 168 & 008 \\
\hline Non-chewer & 27 & $(26.7)$ & 74 & $(73.3)$ & 101 & 1.08 & .008 \\
\hline
\end{tabular}

*Chi-square test 


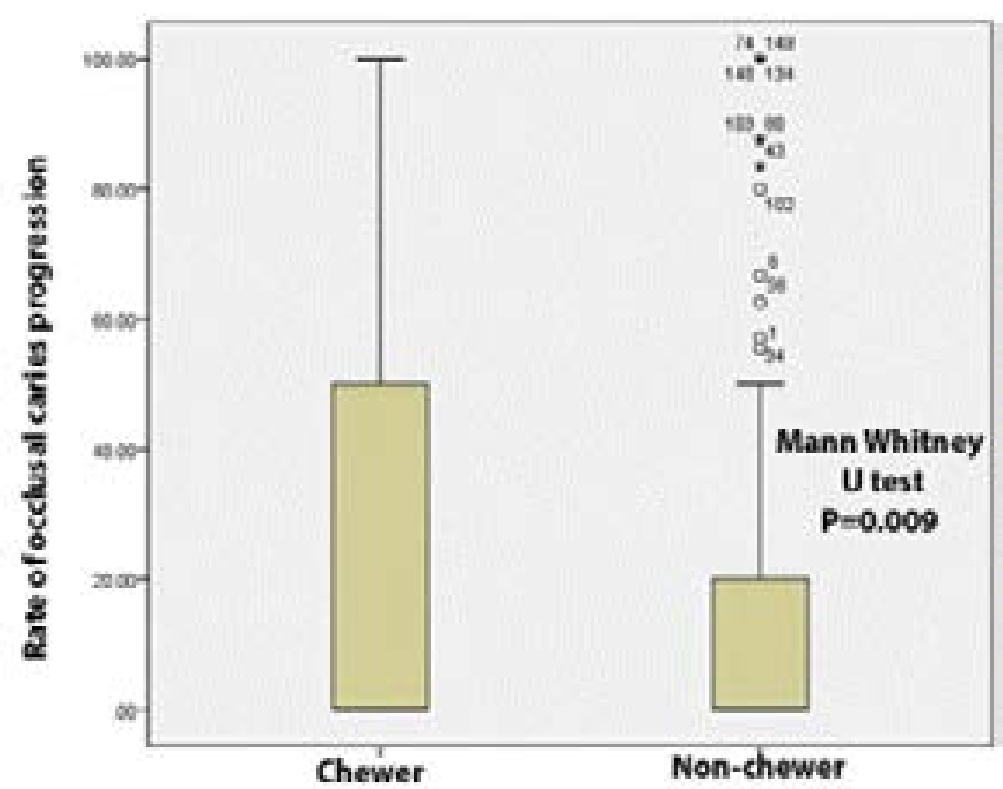

Figure 1 Rate of occlusal caries progression among khat chewers and non-chewers

The occlusal caries progression incidence at chewing side and non-chewing side among khat chewers were 39.8\% and $32.7 \%$ respectively as shown in Table 4 . The differ- ence of the occlusal caries progression rate at chewing side and non-chewing side among khat chewers group was not statistically significant (Fig. 2).

Table 4 Comparison of incidence of occlusal caries progression between chewingside and non-chewing side in khat chewers

\begin{tabular}{|c|c|c|c|c|}
\hline \multirow[t]{3}{*}{ Group } & \multicolumn{4}{|c|}{ Occlusal Caries Progression } \\
\hline & \multicolumn{2}{|c|}{ No progress } & \multicolumn{2}{|c|}{ Progress } \\
\hline & $n$ & $(\%)$ & $n$ & $(\%)$ \\
\hline $\begin{array}{l}\text { Non-Chewing Side } \\
\text { (Right) }\end{array}$ & 66 & $(67.3)$ & 32 & $(32.7)$ \\
\hline Chewing Side (Left) & 59 & $(60.2)$ & 39 & $(39.8)$ \\
\hline
\end{tabular}




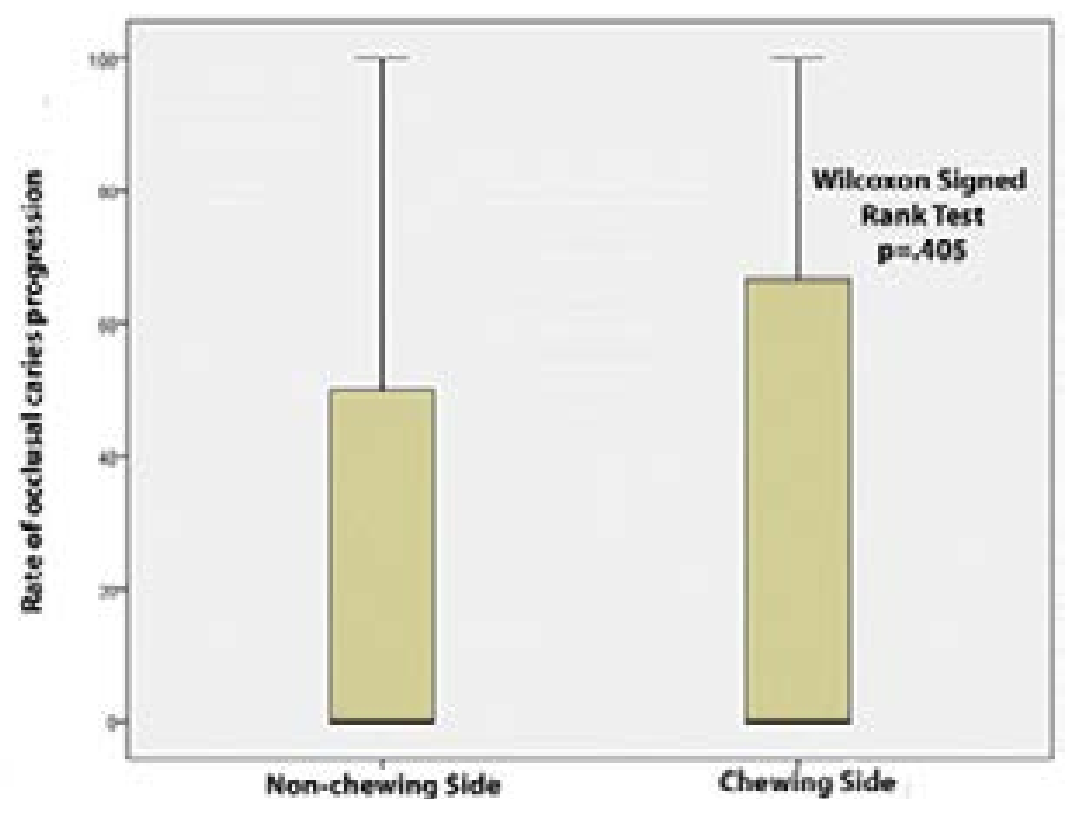

Figure 2 Rate of occlusal caries progression among khat chewers at chewer side and non-chewer side

Relative risk analysis based on socio-demographic variables was carried out using bivariate analysis as shown in Table 5. Results showed no significant differences in relative risk for caries progression between males and females although females showed higher risk of caries progression $(\mathrm{RR}=1.6895 \% \mathrm{CI} 0.80,3.57)$ compared to males
$(\mathrm{RR}=1.32,95 \% \mathrm{CI}$ 0.76-2.31). The adjusted relative risk for income is shown in Table 5. Participants with income below YR40000 had the highest risk for occlusal caries progression. Participants with high school education or lower had the highest risk for occlusal caries progression (Table 5).

Table 5 Bivariate analysis of confounding effect of socio-demographic variables

\begin{tabular}{|c|c|c|c|c|}
\hline \multirow[t]{2}{*}{ Socio-demographic variables } & \multirow{2}{*}{$\begin{array}{l}\text { RR } \\
\text { (Adjusted) }\end{array}$} & \multicolumn{2}{|c|}{$\begin{array}{l}\text { 95\% Confidence } \\
\text { Interval }\end{array}$} & \multirow[t]{2}{*}{ P-value } \\
\hline & & Lower & Upper & \\
\hline \multicolumn{5}{|l|}{ Gender } \\
\hline Male & 1.33 & 0.76 & 2.31 & \multirow{2}{*}{.112} \\
\hline Female & 1.69 & 0.80 & 3.57 & \\
\hline \multicolumn{5}{|l|}{ Income (Yemeni Rial) } \\
\hline Less than 40,000 & 3.64 & 1.82 & 7.29 & \multirow{4}{*}{$.011 *$} \\
\hline $41,000-70,000$ & 1.22 & 0.63 & 2.38 & \\
\hline $71,000-100,000$ & 1.16 & 0.40 & 3.41 & \\
\hline More than 100,000 & 0.46 & 0.16 & 1.37 & \\
\hline \multicolumn{5}{|l|}{ Education } \\
\hline Primary, Secondary \& High school & 3.41 & 1.18 & 9.87 & \multirow{3}{*}{$.006^{*}$} \\
\hline College & 1.75 & 1.00 & 3.05 & \\
\hline University Degree \& Postgraduate & 1.13 & 0.54 & 2.35 & \\
\hline
\end{tabular}

*Mantel-Haenszel test 
The effect of khat chewing on occlusal caries progression by controlling the confounding variables of selected demographic and oral health related variables was further investigated using binary logistic regression (LR). The stepwise Forward LR procedure was chosen as it is designed to find a set of predictors that are significant in predicting the dependent variable. In this analysis, occlusal caries progression incidence (a discrete binary variable) was assigned as the dependent or outcome variable, where caries progression is given a value of 1 and no caries progression a value of 0 . Khat chewing status, selected demographic variables (gender, income, and education) and oral health related variables (oral health knowledge, oral hygiene practice, and sugar intake) were entered into the regression analysis as independent variables or predictors. Income and education were re-categorized into dummy variables. The interactions between khat chew- ing and other predictor variables were also performed to investigate the interaction effects of khat chewing with these variables. The results are presented in Table 6.

The classification accuracy rate was found to be $73.0 \%$, which was greater than the proportional by chance accuracy criteria of $54.4 \%$. This shows that the classification accuracy criterion is satisfied. The regression results indicate that knowledge of oral hygiene and oral hygiene practice were statistically significant predictors of caries progression; khat chewing was the only statistically predictor for those whose income was less than YR40000 (-2 $\log 2(11)=37.894, \mathrm{p} \chi$ Likelihood $=216.397 ;<.0001)$. The odds of those with occlusal caries progression incidence was 5.12 times higher in khat chewers with an income less than YR40000 than those of any other categories. The model explained 24.2\% (Nagelkerke R2) of the variance in caries progression and correctly classified $73 \%$ of cases. 
Table 6 Logistic regression analysis of caries progression

\begin{tabular}{|c|c|c|c|c|c|}
\hline Independent variables & $\mathrm{B}$ & $\mathrm{SE}$ & Wald & Sig. & $\operatorname{Exp}(\mathrm{B})$ \\
\hline Gender & .438 & .414 & 1.123 & .289 & 1.550 \\
\hline Income (Yemeni Rial) & & & 4.339 & .227 & \\
\hline Less than 40,000 & -.756 & .637 & 1.411 & .235 & .469 \\
\hline $41,000-70,000$ & .429 & .670 & .410 & .522 & 1.536 \\
\hline $71,000-100,000$ & .218 & .766 & .081 & .776 & 1.244 \\
\hline Education & & & 1.470 & .479 & \\
\hline Primary, Secondary \& High School & -.161 & .547 & .087 & .768 & .851 \\
\hline College & .364 & .420 & .751 & .386 & 1.438 \\
\hline Knowledge of Oral Hygiene & -.616 & .250 & 6.079 & .014 & .540 \\
\hline Oral Hygiene Practice & -1.313 & .475 & 7.630 & .006 & .269 \\
\hline Income (Yemeni Rial) * Chewing status & & & 8.018 & .046 & \\
\hline Less than 40,000 by Chewing(Chewers) & 1.639 & .593 & 7.648 & .006 & 5.149 \\
\hline $41,000-70,000$ by Chewing(Chewers) & .211 & .712 & .088 & .767 & 1.235 \\
\hline $71,000-100,000$ by Chewing(Chewers) & -.227 & .898 & .064 & .801 & .797 \\
\hline Constant & 3.376 & 1.365 & 6.117 & .013 & 29.255 \\
\hline
\end{tabular}

\section{Discussion}

Dental caries is perhaps the most ubiquitous disease that has affected mankind. While it is not normally a mortal condition, it can cause a great deal of pain and suffering, and the loss of teeth has profound consequences in terms of eating, speaking, and social behavior in general ${ }^{8}$. Previous studies, ${ }^{4,-10}$ have suggested that khat chewing is associated with dental caries. However, those studies were cross-sectional and in vitro studies which provide low level of evidence. Thus, the current study is the first attempt to evaluate occlusal caries progression among khat chewers using cohort study.
The finding of the current study suggests that khat chewing increases the risk of occlusal caries progression. In vitro study found that khat can cause enamel demineralization and this, perhaps explains on how chewing khat can increase the risk of dental caries ${ }^{4}$. It may also due to the effect of khat on the salivary flow, where it has been found that khat chewers exhibited low salivary flow rate ${ }^{11}$, which has been reported that low salivary flow rate contributes to the development of dental caries ${ }^{12}$.

Although the chewers chewed khat on the left side of the mouth, no significant difference in the progression of occlusal caries was found in the study. Wyne ${ }^{13}$ observed 
that there is a high probability of a bilateral occurrence of caries especially for molars teeth. Since this study only included molars therefore the chances for bilateral progression would also be similar. Moreover, the acidity of khat is capable of leaching over the mouth via saliva and distributing the acidity. It is an expected finding as there is the same environment for all the teeth in a mouth; thus, the remineralization and demineralization processes are the same. This assumption requires for subsequent profound research in the framework of an extensive longitudinal study.

In this study, the confounding factors i.e sugar intake, oral hygiene practice and oral health knowledge were controlled. After controlling the confounding factors, khat chewers with low income, less than YR40.000 per month were more likely to have high occlusal caries progression. This finding is not surprising, since socioeconomic status is known to be associated dental caries ${ }^{14}$. Furthermore, large number of reports over the past few decades has demonstrated that social and behavioral factors are associated with dental caries and some studies have specifically indicated that dental caries can now be regarded as a disease of poverty ${ }^{15}$.

It has been suggested that caries progression should be monitored at 3, 6, 9 months intervals after the baseline ${ }^{16}$. The present study only measured the progression of dental caries at 3 months after the baseline. Although the follow up was only done at 3 months, it showed that khat chewing contribute to the risk for dental caries. It is expected that the risk will increase if follow up is done at 6 and 9 months.

There were several limitations in this study. The characteristics of the chewers and non- chewers were significantly different especially gender. It was difficult to match them in term of gender, since most males are chewers and less women are chewers. However, this factor was controlled at the analysis. The duration of follow up was short. The initial plan was to follow up to 6 months, however due to the crisis in Yemen, most of the participants could not be retrieved.

\section{Conclusion}

Within the limitation of this study, it can be concluded that khat chewing habit can be considered a risk factor for dental caries especially to those in low economic status. There is no significant difference in occlusal caries progression at chewing and non-chewing side among Yemeni khat chewers. Thus, dental practitioners must motivate their patients who chew khat especially among those who in low socio-economic to stop khat chewing habits.

\section{Conflict of interest}

The authors declare no potential conflicts of interest with respect to the authorship and/or publication of this article.

\section{Acknowledgements}

This study was funded by University of Malaya (PS3852010A).

\section{References}

1. Goldenberg D, Lee J, Koch WM, Kim MM, Trink B, Sidransky D, et al. Habitual risk factors for head and neck cancer. Otolaryngol Head Neck Surg. 2004;131(6):986-93.

2. Kalix P, Braenden O. Pharmacological aspects of the chewing of khat leaves. Pharmacol Rev. 1985;37(2):149-64. 3. Stevenson M, Fitzgerald J, Banwell C. Chewing as a social act: cultural displacement and khat consumption in the East African communities of Melbourne. Drug Alcohol Rev. 1996;15(1):73-82.

4. Al-Alimi K. An Evaluation of Demineralization Potential of Qat Extracts on smooth enamel surface and at Composite Restoration Interface. MDSc Thesis. Malaysia: University of Malaya; 2008.

5. Ekstrand KR, Ricketts DNJ, Kidd EAM. Reproducibility and accuracy of three methods for assessment of demineralization depth on the occlusal surface: An in vitro examination. Caries Res. 1997;31(3): 224-231.

6. Wright BD, Linacre JM. Reasonable mean square fit values. Rasch Meas Trans. 1994;8:370.

7. Duncan PW, Bode RK, Lai SM, Perera S, Glycine Antagonist in Neuroprotection Americas Investigators. Rasch analysis of a new stroke-specific outcome scale: The stroke impact scale. Arch Phys Med Rehabil. 2003;84(7):950-963.

8. Kidd E, Giedrys-Leeper E, Simons D. Take two dentists: a tale of root caries. Dent update. 2000;27(5):222-30. 9. Hill CM, Gibson A. The oral and dental effects of q'at chewing. Oral Surg Oral Med Oral Pathol. 1987;63(4):43336.

10. Al-Sharabi AK. Oral and paraoral lesion caused by qat chewing: phD Thesis. Sudan University Khartoum . 2002. 11. Al-Alimi KR, Abdul Razak AA, Saub R. Salivary car- 
ies parameters: Comparative study among Yemeni khat chewers and nonchewers. J Dent Sci. 2014;9(4):328-31. 12. Dawes C. Physiological factors affecting salivary flow rate, oral sugar clearance, and the sensation of dry mouth in man. J Dent Res. 1987;66 Suppl 2:648-53.

13. Wyne AH. The bilateral occurrence of dental caries among 12-13 and 15-19 year old school children. J Contemp Dent Pract. 2004;5(1):42-52.
14. Burt BA, Eklund SA. Dentistry, dental practice, and the community. $6^{\text {th }}$ ed. Elsevier Health Sciences; 2005. 15. Petersen PE. Sociobehavioural risk factors in dental caries-international perspectives. Community Dent Oral Epidemiol. 2005;33(4):274-79.

16. Aljehani A, Bamzahim M, Yousif MA, Shi XQ. In vivo reliability of an infrared fluorescence method for quantification of carious lesions in orthodontic patients. Oral Health \& Prevent Dent. 2006;4(2):145-50. 